Research Paper

\title{
Influences of wake-effects on bubble dynamics by utilizing micro-pin-finned surfaces under microgravity
}

\author{
Baojin Qi ${ }^{a, b}$, Jinjia Wei ${ }^{a, b, *}$, Xueli Wang ${ }^{\text {a,b }}$, Jianfu Zhao ${ }^{c}$ \\ a School of Chemical Engineering and Technology, Xi'an Jiaotong University, Xi'an 710049, China \\ ${ }^{\mathrm{b}}$ State Key Laboratory of Multiphase Flow in Power Engineering, Xi'an Jiaotong University, Xi'an 710049, China \\ ${ }^{\mathrm{c}}$ Key Laboratory of Microgravity (National Microgravity Laboratory)/CAS, Institute of Mechanics, Chinese Academy of Sciences, Beijing 100190, China
}

\section{H I G H L I G H T S}

- Wake field has little impact on bubble dynamics at low heat flux in microgravity.

- Liquid flow caused by wake-effects promotes bubble release at moderate heat flux.

- Vapor columns form and merge with departure bubble before release at high heat flux.

- Interaction between microstructure and wake-effects can enhance heat transfer.

- Theoretical analyses show that bubble is constantly influenced by wake field.

\section{A R T I C L E I N F O}

\section{Article history:}

Received 3 August 2016

Revised 30 October 2016

Accepted 18 November 2016

Available online 21 November 2016

\section{Keywords:}

Wake-effects

Microgravity

Micro-pin-fins

Pool boiling

Bubble dynamics

\begin{abstract}
A B S T R A C T
The influences of wake on bubble dynamics under various heat fluxes have been studied in microgravity. Nucleate pool boiling experiments of FC-72 on silicon chips fabricated with micro-pin-fins were conducted in $10^{-3}$ gravitational acceleration for $3.6 \mathrm{~s}$. Experimental results indicated that wake field had little influence on bubble dynamics at low heat flux, $q=12.53 \mathrm{~W} / \mathrm{cm}^{2}$, but its effects on bubble dynamics became very great at moderate heat flux, $q=27.89 \mathrm{~W} / \mathrm{cm}^{2}$, and high heat flux, $q=39.54 \mathrm{~W} / \mathrm{cm}^{2}$. More importantly, wake-effects appeared even more significant in microgravity. In the wake field, the horizontal flow of the liquid on micro-pin-finned silicon chips promoted the collision, coalescence and movement of bubbles, and the vertical flow of liquid phase exerted an upward force on bubbles, which can effectively shorten the growth cycle and decrease the departure radius of bubbles. Furthermore, fresh liquid could easily be inhaled into the micro-pin-finned structure owning to the negative pressure in wake region, which can supply sufficient liquid for the growth of bubble, avoiding film boiling. The interaction between the micro-pin-finned structure and the wake effect promoted the process of bubble coalescence and departure effectively, so the process of heat transfer was significantly improved on micro-pin-finned surface. In addition, the flow field and bubble behavior in wake region were also briefly analyzed based on some reasonable simplifications and hypotheses. The theoretical analyses showed that the durations of wake-effects lasted longer than the time periods of the bubble in next generation, and the bubble diameters were also smaller than the thickness of wake region. Therefore, the dominant bubble of next generation was influenced by the wake field during its ebullition cycle, which is consistent with the experimental phenomenon.
\end{abstract}

(c) 2016 Elsevier Ltd. All rights reserved.

\section{Introduction}

Nucleate pool boiling is known as one of the most effective modes of heat transfer owing to the latent heat transport during liquid evaporation, which allows it to achieve orders of magnitude

\footnotetext{
* Corresponding author at: School of Chemical Engineering and Technology, Xi'an Jiaotong University, Xi'an 710049, China.

E-mail address: jjwei@mail.xjtu.edu.cn (J. Wei).
}

enhancement in heat transfer coefficient and low temperatures of the heat dissipating device compared to single-phase counterparts. Nucleate pool boiling has been widely employed in many terrestrial heat transfer systems such as desalination, power generation, electronic components cooling, and various energy conversion systems [1]. As technology advances toward the exploration and development of space, the use of micro-electronic devices is getting wider and wider in spacecraft, resulting in a rapid increasing of power dissipation rate at the chips, module and system levels. 


\begin{tabular}{|c|c|c|c|}
\hline \multicolumn{4}{|c|}{ Nomenclature } \\
\hline$a_{\mu}$ & $\begin{array}{l}\text { acceleration of rising bubble at the microgravity condi- } \\
\text { tion, } \mathrm{m} \cdot \mathrm{s}^{-2}\end{array}$ & $\begin{array}{l}T_{\text {sat }} \\
T_{\mathrm{w}}\end{array}$ & $\begin{array}{l}\text { saturation temperature, }{ }^{\circ} \mathrm{C} \\
\text { wall temperature, }{ }^{\circ} \mathrm{C}\end{array}$ \\
\hline$c$ & integral constant & $\Delta T_{\text {sub }}$ & liquid subcooling, ${ }^{\circ} \mathrm{C}$ \\
\hline$C_{D}$ & drag coefficient & $u$ & horizontal velocity, $\mathrm{m} \cdot \mathrm{s}^{-1}$ \\
\hline$D_{\mathrm{d}}$ & departure diameter, $\mathrm{mm}$ & $U$ & horizontal velocity closed to the bubble bottom, $\mathrm{m} \cdot \mathrm{s}^{-1}$ \\
\hline$e$ & natural logarithm & $U_{H}$ & heating voltage, $\mathrm{V}$ \\
\hline$F_{\mathrm{b}}$ & buoyancy force, $\mathrm{N}$ & $v$ & vertical velocity, $\mathrm{m} \cdot \mathrm{s}^{-1}$ \\
\hline$F_{\mathrm{d}}$ & drag force, $\mathrm{N}$ & $v_{b}$ & ultimate rising velocity of bubble, $\mathrm{m} \cdot \mathrm{s}^{-1}$ \\
\hline$F_{\mathrm{i}}$ & inertia force, $\mathrm{N}$ & V & vertical velocity closed to the bubble bottom, $\mathrm{m} \cdot \mathrm{s}^{-1}$ \\
\hline$F_{\mathrm{M}}$ & Marangoni force, $\mathrm{N}$ & $y$ & vertical coordinate, $\mathrm{mm}$ \\
\hline$F_{\mathrm{p}}$ & pressure difference, $\mathrm{N}$ & $I_{H}$ & heating current, A \\
\hline$F_{\mathrm{s}}$ & interfacial tension, $\mathrm{N}$ & $\delta$ & thickness of wake field, mm \\
\hline$F_{\text {net }}$ & net force, $\mathrm{N}$ & $\delta_{0}$ & maximum thickness of wake field, mm \\
\hline$g_{0}$ & $\begin{array}{l}\text { gravitational acceleration in the terrestrial condition, } \\
\mathrm{m} \cdot \mathrm{s}^{-2}\end{array}$ & $\begin{array}{l}\Delta \\
\Delta_{T}\end{array}$ & $\begin{array}{l}\text { thickness of microlayer, mm } \\
\text { thickness of thermal boundary layer, } \mathrm{mm}\end{array}$ \\
\hline$g_{\mu}$ & gravitational acceleration in the microgravity condition, & $\zeta$ & dimensionless number, $\zeta=y / \delta(\tau)$ \\
\hline$\dot{m}$ & incremental mass of liquid in an element, $\mathrm{kg}$ & $\eta$ & $\begin{array}{l}\text { dimensionless number, } \zeta=D_{\mathrm{d}} / 2 r \\
\text { dynamic viscosity, } \mathrm{Pa} \cdot \mathrm{s}\end{array}$ \\
\hline$\dot{m}_{\text {in }}$ & liquid flowing into an element, $\mathrm{kg}$ & $\rho_{l}$ & liquid density, $\mathrm{kg} \cdot \mathrm{m}^{-3}$ \\
\hline$\dot{m}_{\text {out }}$ & liquid flowing out of an element, $\mathrm{kg}$ & $\rho_{v}$ & vapor density, $\mathrm{kg} \cdot \mathrm{m}^{-3}$ \\
\hline $\operatorname{Pr}$ & Prandtl number & $\tau$ & duration of microgravity, $\mathrm{s}$ \\
\hline$P_{\mathrm{S}}$ & the system total pressure, $\mathrm{Pa}$ & $\tau_{0}$ & duration of wake-effects, $s$ \\
\hline$q$ & heat flux, $\mathrm{W} \cdot \mathrm{m}^{-2}$ & $\tau_{l}$ & time required for bubble to reach $v_{b}, \mathrm{~m} \cdot \mathrm{s}^{-1}$ \\
\hline$r$ & radius of rising bubble, $\mathrm{mm}$ & & \\
\hline$T_{\mathrm{b}}$ & temperature of bulk liquid, ${ }^{\circ} \mathrm{C}$ & & \\
\hline
\end{tabular}

Electronic cooling by using boiling system in space vehicles and in earth orbiting station has become an increasing significant subject due to its high efficiency in heat transfer [2-4].

The dynamics studies in microgravity, concerning such fundamental processes as bubble nucleation, growth, coalescence and departure on a heated wall are essential for revealing the action mechanism of nucleate pool boiling [3]. Previous studies have noted that the dynamic behavior of bubbles is strongly influenced by many factors such as the surface geometry of heater [5-14], thermocapillary convection [15-20] non-condensate gas [16-21], and the gravity level [22-28], and the effects of these factors have been reported in several research literatures.

The bubble dynamics of phase change heat transfer is a strong function of the surface geometry of the heater. Some investigators [5-9] conducted pool boiling experiments on single strand wire and various braid wires in the absence of gravity. Zhao and coworkers [6,7] observed three critical bubble diameters on thin wire in microgravity, dividing the whole range of the observed bubbles into four regimes. Koeln and Munro's experiments [8,9] showed that the braided wire heating element enhances bubble generation and conduction-induced thermal gradients within the water by reducing the heat flux needed for bubble incipience and the average wire temperature in microgravity. Besides, several investigators [10-14] have reported their research work of nucleate boiling on various chips under microgravity conditions. Different from the experimental results on the ground, most fabrication of microstructures on the chip surfaces showed the drawback of severe deterioration in boiling heat transfer in the high heat flux region. Conversely, a more recent study on nucleate boiling on micro-pin-finned surface was experimentally investigated by Xue and Zhang [11,12], and some exciting results were reported. It was found that micro-pin-finned structure promoted the growth, coalescence and detachment of bubbles, and the mean temperature of micro-pin-finned surface kept almost steady or quasisteady state under microgravity conditions.
Some researchers [15-20] postulated that thermocapillary or Marangoni convection, typically masked by dominant buoyancydriven convection in terrestrial conditions, plays a significant role in bubble nucleation and growth in microgravity, and therefore influences heat transfer effectiveness. These convection effects are the result of fluid motion along the vapor-liquid interface and away from the heater surface, induced by surface tension gradients. Straub [16] suggested that non-condensable gasses caused Marangoni convection, leading to the departure of bubbles, while Aktinol's experiments [17] showed that the variation of capillary flow induced from non-condensable gas was very small and the resulting capillary flow had only a second order effect on the flow field. Moreover, Kannengieser [18] and Zhao et al. [19,20] further proposed that these gasses were not the only cause of Marangoni convection, but Henry et al. [21] suggested that non-condensable gases actually decreased the strength of Marangoni convection.

A number of research results have shown that the processes of bubble growth, coalescence and departure of bubble were significantly affected by gravity level [22-28]. Dhir and co-workers $[22,23]$ performed experimental and numerical researches of bubble dynamics under short/long-term microgravity conditions. They found, under short period of microgravity, that bubble departure diameter and growth period can be approximately related to the gravity level, longer growth period and larger diameter under a smaller reduced gravity conditions. Straub's experiment $[16,24]$ showed that steady state $0 \mathrm{~g}$ boiling was up to $15 \%$ more efficient in microgravity when the heat transfer coefficients of each gravity level were compared. On the contrary, Zhao et al. $[5,7,19,25]$ concluded that the heater temperature at the onset of boiling was weakly dependent or independent of gravity because boiling occurred at the same temperature set-point for both gravity levels.

In addition, some investigators performed simulations and experiments of bubble dynamics in pool boiling under various gravity levels by taking into account the effects of fluid's surface tension $[17,29,30]$, system pressure $[27,28]$, super heat 
$[10,18,31]$, heat flux $[11,12]$, liquid subcooling $[10,22,28]$ etc. some interesting results have been reported systematically.

Despite extensive research over a span of several decades, the studies on bubble dynamics in pool boiling, especially on the interactions between bubbles which may have a far greater impact on bubble dynamics and heat transfer, is still in its infancy. Bubble wake-effects, one of the most important interactions between bubbles, has been proved to be a significant factor influencing bubble dynamics and heat transfer in boiling experiment under terrestrial condition. However, the buoyancy effect becomes weak in microgravity, resulting in a larger size and much lower velocity for the bubble departure. Thus, the distribution of velocity and temperature fields in boiling vessel is obviously different from those in normal gravity, and the bubble behaviors is also changed dramatically under reduced gravity. However, the research on the influences of wake-effects on bubble dynamics is still not fully understood, and further investigations are required. Furthermore, there is a lack of analytical techniques in the literatures to provide a quantitative measurement of interactions between bubbles in boiling video data.

In the present study, to investigate the influence of bubble wake-effects on the relation between heat flux and bubble behaviors, nucleate pool boiling experiments of FC-72 from silicon chips fabricated with micro-pin-fins are conducted utilizing the drop tower in the National Microgravity Laboratory, Chinese Academy of Sciences, Beijing, which can provide a gravity level of $10^{-3} \mathrm{~g}_{0}$ (here $\mathrm{g}_{0}$ are the gravitational acceleration under terrestrial conditions, $g_{0}=9.81 \mathrm{~m} / \mathrm{s}^{2}$ ) with duration of about $3.6 \mathrm{~s}$. In this paper, based on the visual experiments of detailed bubble wake-effects on the heating source, the change of the dynamic behaviors of bubble coalescence and departure are discussed in dynamics relating to the heat flux and the structure of the micro-pin-finned surfaces. In addition, the flow field and bubble behavior in wake region were also briefly analyzed based on some reasonable simplifications and hypotheses.

\section{Experimental apparatus and test procedure}

\subsection{Experimental apparatus}

The pool boiling test facility system designed for conducting drop-tower experiments is shown schematically in Fig. 1. A $100 \mathrm{~mm} \times 100 \mathrm{~mm} \times 100 \mathrm{~mm}$ boiling chamber made of polycarbonate for visualizing boiling phenomena, is filled with about $1 \mathrm{~L}$ air-dissolved FC-72, the test liquid, at saturation temperature $\left(T_{\text {sat }}\right)$ of $56^{\circ} \mathrm{C}$ and under atmospheric pressure. A rubber bag attached to the test vessel is used to maintain a near-atmospheric pressure. By this way, subcooling $\left(\Delta T_{\text {sub }}\right)$ and pressure $\left(P_{\mathrm{s}}\right)$ conditions can vary during the experiments. The bubble behavior is videoed by using a $25 \mathrm{~Hz}$ CCD camera installed in front of the test vessel at a direction angle towards to the heater surface for visual observation. Simultaneously, a high speed digital camera (VIT-cam CTC) imaging 500 frames per second at a resolution of $1024 \times 640$ pixels, with a shutter speed of $1 / 2000 \mathrm{~s}$ is adopted together with lens to image the boiling phenomena. A programmable DC power supply is connected in parallel connection to two series resistances $\left(R_{1}=5 \mathrm{k} \Omega\right.$, $R_{2}=100 \mathrm{k} \Omega$,) and the test chip. The two series resistances are used to measure the heating voltage $\left(U_{H}\right)$ across the silicon chip in the circuit. Thus, the heating power is calculated based on constant heating current $\left(I_{H}\right)$ and voltage measured across the test chip, and the current is measured by a hall transducer and then the data is transmitted to a data acquisition system.

Details of the test section are shown in Fig. 2. T-type thermocouple with $0.13-\mathrm{mm}$-diameter for measuring the local wall temperature $\left(T_{\mathrm{w}}\right)$ is bonded at center of the bottom surface of the test chip using high thermal conductivity epoxy adhesive. The local temperature of bulk liquid $\left(T_{\mathrm{b}}\right)$ is measured by a 0.3 -mmdiameter
T-type thermocouple positioned about $20 \mathrm{~mm}$ from the edge of the test chip and $40 \mathrm{~mm}$ above the chip level, to avoid effects of bubble dynamics. The change of measured temperature of bulk liquid is less than $0.5 \mathrm{~K}$ during every test run about $90 \mathrm{~min}$. The two thermocouples to measure liquid and wall temperatures are connected to a temperature transmitter, so that voltage signals are collected by a data acquisition system (DI710-UHS), as shown in Fig. 1.

The test chip is a P-doped N-type square silicon chip with the dimensions of $10 \times 10 \times 0.5 \mathrm{~mm}^{3}$. Micro-pin-fins are fabricated on the chip surface to enhance boiling heat transfer by using dry etching technique. The SEM image of micro-pin-fin is shown in Fig. 3. The thickness and height of the fins are $30 \mu \mathrm{m}$ and $60 \mu \mathrm{m}$ respectively (denoted as PF30-60), and the fin spacing (distance between fins) is the same as its thickness. The specific resistance is $1-3 \Omega \mathrm{cm}$, and the thermal conductivity $\mathrm{k}$ is about $120 \mathrm{~W} \cdot \mathrm{m}^{-1}$ $\cdot \mathrm{K}^{-1}$. The chip is Joule heated by a direct current. Two $0.25 \mathrm{~mm}$ diameter copper wires are soldered to the side surfaces at the opposite ends of test chip to supply power for the chip. In order to secure the ohmic contact between the semiconductor silicon chip and the copper wire, a special solder with a melting point at $300{ }^{\circ} \mathrm{C}$ is applied for the silicon chip through ultrasonic bonding method before soldering the copper wires. The test chip is bonded on a $50 \times 50 \times 1.2 \mathrm{~mm}^{3}$ plexiglass plate by using epoxy adhesive and then fixed on the plexiglass base bonded on the bottom of the test vessel, which facilitates the exchange of the silicon chip. The side surfaces of the chip are covered with an adhesive with very small thermal conductivity of $0.12 \mathrm{~W} \cdot \mathrm{m}^{-1} \cdot \mathrm{K}^{-1}$ to minimize heat loss. Therefore, only the upper surface of the chip is effective in heat transfer. Besides, the substrate is made of plexiglass and the thermal conductivity of plexiglass is about $1.0886 \mathrm{~W} \cdot \mathrm{m}^{-1} \cdot \mathrm{K}^{-1}$ that does not vary with temperature.

The uncertainties in chip and bulk liquid temperatures measured by thermocouples are estimated to be less than $0.3 \mathrm{~K}$. Wall temperature uncertainty may result in errors due to thermocouple calibration by using a platinum resistance thermometer $(0.03 \mathrm{~K})$, temperature correction for obtaining surface temperature based on the measured value at the bottom of the chip $(0.2 \mathrm{~K})$, temperature unsteadiness $(0.1 \mathrm{~K})$ and thermocouple resolution (less than $0.1 \mathrm{~K}$ ). Heat flux uncertainty is consisted of the errors of electric power per unit area supplied to the chip, heat loss ratio through substrate conduction and transient effect ratio due to the change of internal energy of chip, respectively. Measurement errors of heat voltage $U_{\mathrm{H}}$, current I and side length 1 are $0.1 \%, 0.014 \%$ and $0.5 \%$, respectively. The heat loss ratio through substrate is about $5.0 \%$ and the transient effect ratio is about $0.3 \%$. So the uncertainty in heat flux is estimated at approximately $6 \%$ for steady boiling heat transfer and $6.3 \%$ for quasi-steady boiling heat transfer. In addition, due to the effect of non-condensable gas on boiling curve, a quantitative comparison was performed in our ground experiments $[32,33]$ revealing that the existence of the dissolved gas reduces the boiling incipient wall superheat and increases the heat flux in low heat flux region. However, the effect of dissolved gas in nucleate boiling region at high heat fluxes can be ignored.

\subsection{Test procedure}

Experiments were conducted under the influence of terrestrial gravity before releasing the drop capsule and then in short-term microgravity during free falling in the drop tower. The facility satisfied the safety criteria to expose the apparatus in the drop capsule in different gravitational environments varying between microgravity (about $10^{-3} \mathrm{~g}_{0}$ ) in the free falling period and high-g level in the deceleration recovery system.

The test chip was heated by setting a constant input current or voltage for the desired heat flux $q$ to initiate boiling on the heater surface. When the heat transfer reached a steady state in about 


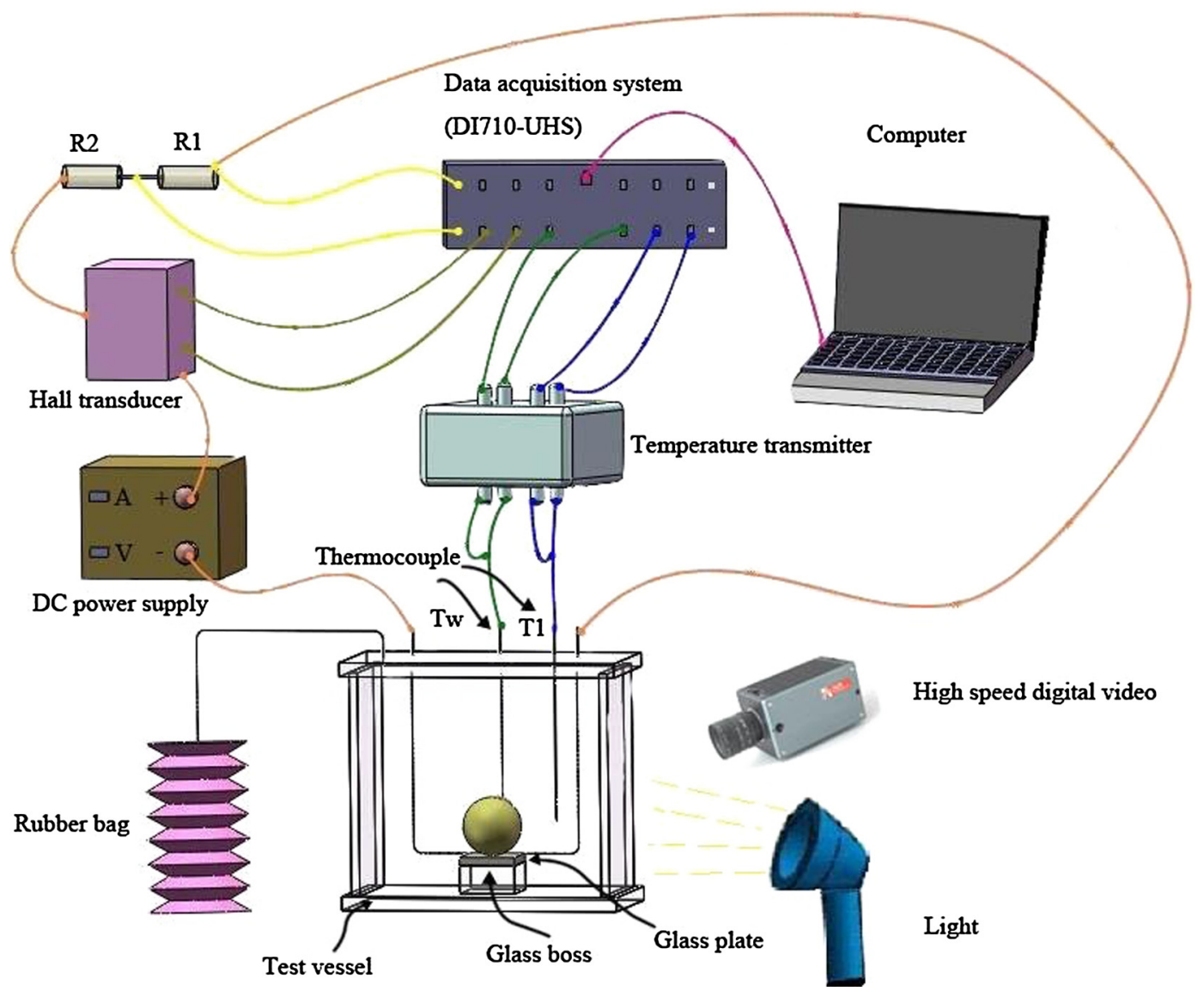

Fig. 1. Schematic diagram of the experimental apparatus.

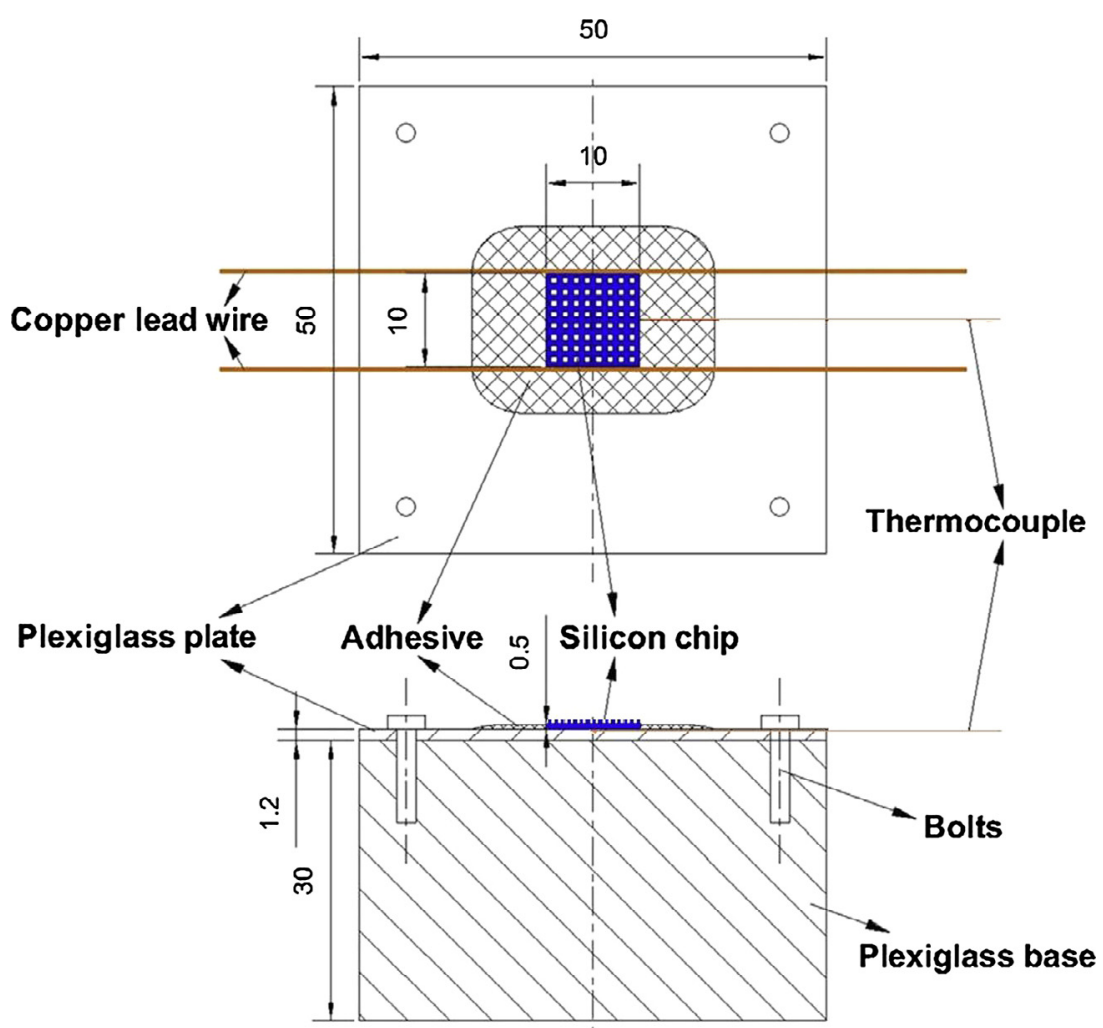

Fig. 2. Details of the test section. 


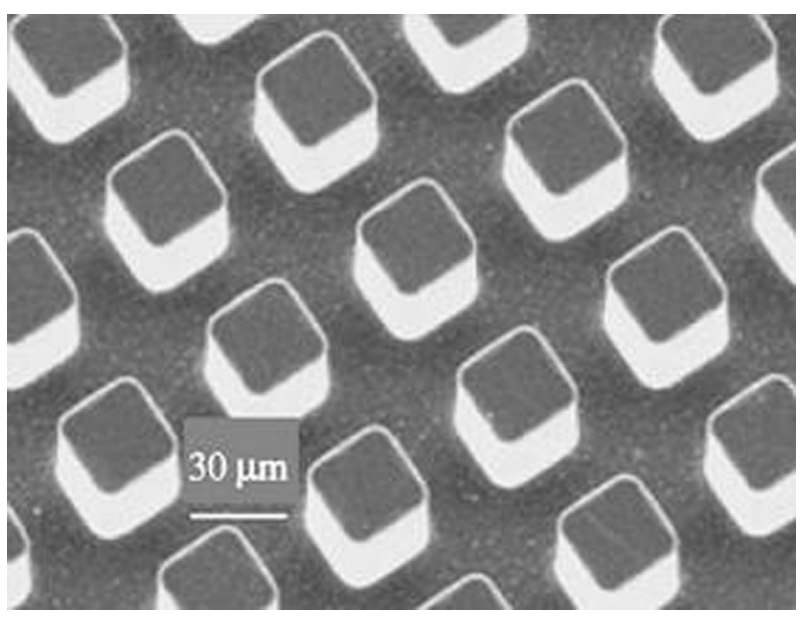

Fig. 3. SEM image of micro-pin-fins.

4 min confirmed by the wall temperature, the free falling of drop capsule started which provided approximately $3.6 \mathrm{~s}$ effective microgravity environment. The high-speed digital camera could work for $8 \mathrm{~s}$ to capture the boiling heat transfer phenomena when an external trigger signal was received. Simultaneously, data measurement and video recording were conducted. As technical reform on the drop tower in Beijing, the experiments were divided into two stages. In the first stage before technical reform, constant direct current method was adopted to heat the silicon chip. After that, in order to attain high heat flux in microgravity, the heating method with constant heating voltage was used to avoid chip damage. As experimental opportunity is limited, only one run was conducted for one heat flux, and the detail experimental conditions were summarized in Table 1 . In addition, to ensure the reproducibility and reliability of the data, identical ground experiments were also conducted for comparison, and the operating conditions were almost identical for both normal gravity and reduced gravity.

The statistical data of bubble departure radius from experimental results could be analyzed by two main steps: the 1 st step, video of the bubble behavior by employing a high speed digital camera is saved in BMP format; the 2nd step, find out the corresponding bubble detachment pictures by employing MATLAB software, which can read the bubble diameter from image in pixels.

\section{Results and discussions}

In boiling experiments, bubbles will detach from the heating surfaces under the action of buoyancy when the bubble volume reach a critical value, forming a low pressure region behind the bubble, called wake region. The bubble behaviors during this process are significantly impacted by heat flux and the structure of micro-pin-finned surfaces.

\subsection{Influence of wake-effects on bubble behaviors at low heat flux}

The transition of bubble behavior on the micro-pin-finned surface responding to the variation of gravity level under low heat flux (Run ${ }^{\#} 1, q=12.53 \mathrm{~W} / \mathrm{cm}^{2}$ ) are shown in Fig. 4 . The time for entering the microgravity condition is set to $0 \mathrm{~s}$ and before this free-fall the time is shown as minus value. It was observed that before entering the microgravity condition, the vapor bubbles generated and detached continuously from the heating surface at a steady state due to the effect of buoyancy force (see Fig. 4a). Because of the small size of the departure bubbles, there was no obvious wake-effects existed behind them. After entering the microgravity condition the bubble detachment was delayed but growth remained (as shown in Fig. 4b), then small bubbles began to coalesce with each other to form a large spherical one (see Fig. 4c), called dominant bubble. The process of coalesce among neighboring small bubbles still played leading role for the dominant bubble growth until it reached the departure size. Subsequently, the dominant bubble departed from the heater surface under the action of the total net force $F_{\text {net }}$ (Equation of $F_{\text {net }}$ is detailed in Section 3.4), forming a small but observable wake region behind the bubble (as shown in Fig. $4 \mathrm{~d}-\mathrm{f}$, from $\tau=0.784$ to $\tau=1.180 \mathrm{~s}$ ). The pressure in the wake region was lower than that in other areas, and the surrounding subcooled fluid flowed into this low pressure area at a low horizontal velocity. The small original bubbles on heating surface were cooled by the subcooled liquid, resulting in slight volumes shrinkage. Then, the original bubbles started expanding again as the impact of wake-effects waned. Because of the combined action of forces and wake field, the dominant bubble changed from sphere to ellipsoid with a vertical major axis and then to ellipsoid with horizontal major axis. This change in shape repeated periodically during the initial stage of the bubble departure. Later, the bubble gradually restored original round shape owing to the influence of surface tension and fluid drag.

Due to the low heat flux, the bubble departure diameter was small $\left(D_{\mathrm{d}}=6.02 \mathrm{~mm}\right)$, and the cavity volume in wake region was also very limited. The buoyancy and inertia forces were wakened seriously in microgravity so the bubble rose with an extremely low velocity. For these two reasons, the intensity of bubble wake was very low and short-lasting (last only about $0.382 \mathrm{~s}$ ). Compared with the short time duration of wake-effects, the formation of next dominant bubble would follow a long time and slow expansion process, so ebullition cycle of this bubble was almost entirely unaffected by the wake-effects.

\subsection{Influence of wake-effects on bubble behaviors at moderate heat flux}

With the increase of heat flux (Run ${ }^{\#} 2$, moderate heat flux, $q=27.89 \mathrm{~W} / \mathrm{cm}^{2}$ ), more nucleation sites were activated, and nucleate boiling tended to be more strenuous in both normal gravity and microgravity. Before the beginning of the microgravity condition, the vapor bubbles kept generating and detaching, as shown in Fig. 5a, which was similar to the case at low heat flux, only the bubble number increased with the increasing of heat flux. When entering microgravity condition, the small original bubbles on chip surface grew radially up to some larger bubbles, and these bubbles merged together to form a dominant spherical bubble in $0.092 \mathrm{~s}$ (see Fig. 5b). This dominant bubble continued to grow through the merging process with the small bubbles next to its lower part, which was also similar to the phenomena under low heat flux. The dominant bubble could hold its spherical shape during the initial stage of growth process, but the tail region of the bubble was stretched slightly before departure due to the attachment to the

Table 1

Experimental conditions of chip PF30-60 in microgravity.

\begin{tabular}{|c|c|c|c|c|c|}
\hline Run $^{\#}$ & Pressure $P(\mathrm{kPa})$ & Subcooling $\Delta T_{\text {Sub }}(\mathrm{K})$ & Heating voltage $U_{H}(\mathrm{~V})$ & Heating current $I_{H}(\mathrm{~A})$ & Heat flux $q\left(\mathrm{~W} \cdot \mathrm{cm}^{-2}\right)$ \\
\hline 1 & 102.9 & 42.2 & 36.9 & 0.34 & 12.53 \\
\hline 2 & 101.4 & 32.4 & 54.8 & 0.51 & 27.89 \\
\hline 3 & 101.7 & 32.1 & 66.0 & 0.60 & 39.54 \\
\hline
\end{tabular}




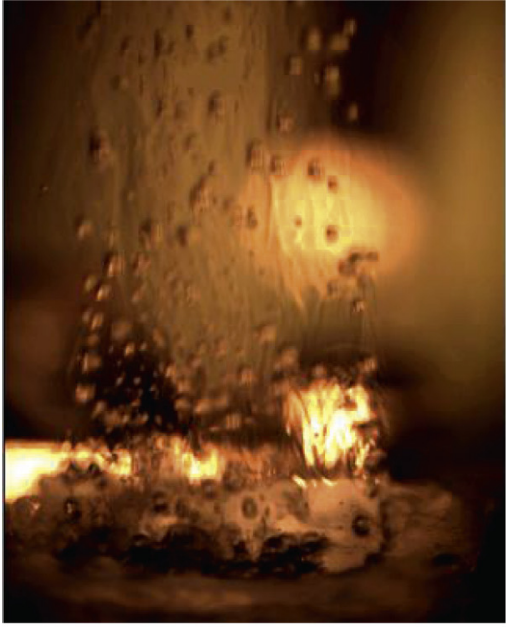

(a) $\tau=-1.062 \mathrm{~s}$

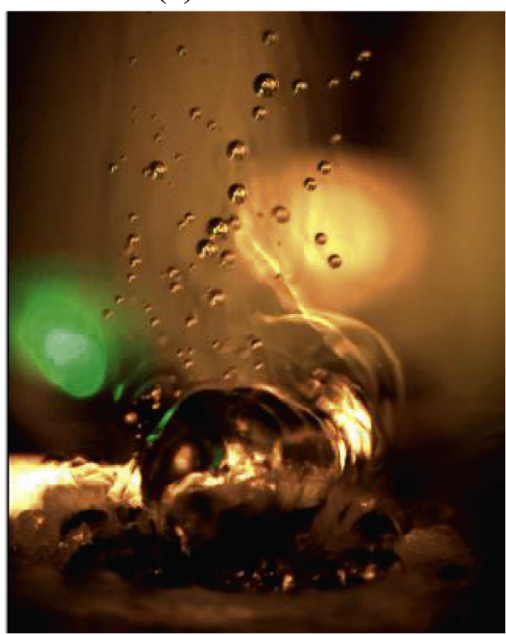

(c) $\tau=0.636 \mathrm{~s}$

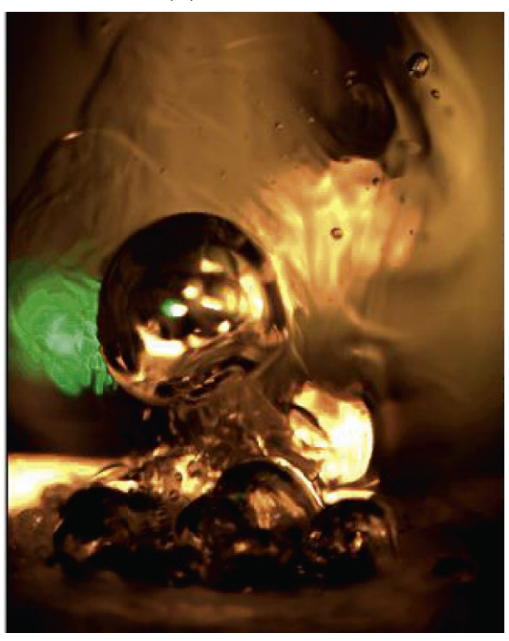

(e) $\tau=0.996 \mathrm{~s}$

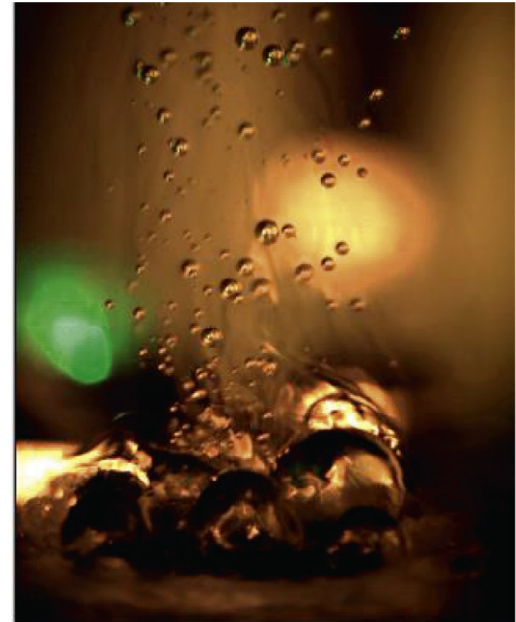

(b) $\tau=0.408 \mathrm{~s}$

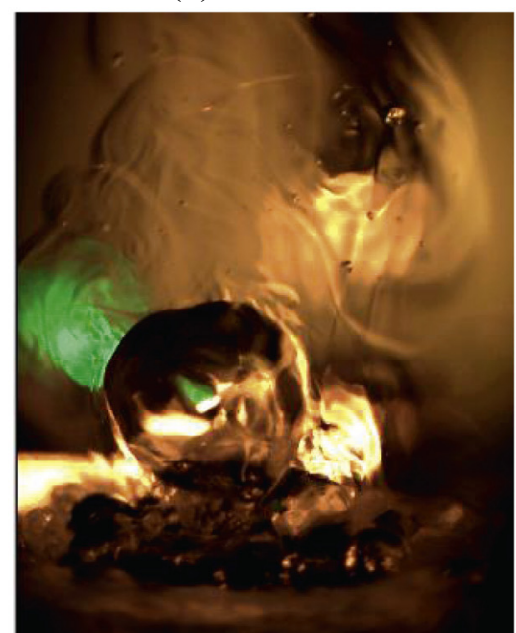

(d) $\tau=0.784 \mathrm{~s}$

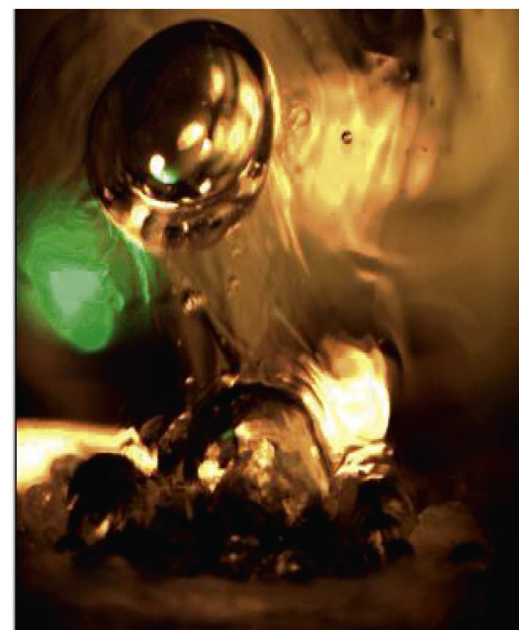

(f) $\tau=1.180 \mathrm{~s}$

Fig. 4. The transition of bubble behavior at low heat flux.

test section, as shown in Fig. 5c. After detaching from the heat surface, the trailing edge of the dominant bubble shrunk rapidly, forming a hemispherical bubble with a nearly flat bottom (see Fig. 5d). The rising bubble caused a large wake region behind it. Due to the obvious increase of detachment frequency and a larger departure radius of dominant bubble, the duration and influence range of the wake-effects were both increased significantly. The pressure gradient as well as the entrainment of vortexes drove the surrounding subcooled fluid into the wake region, and the small bubbles of new generation on heating surface were cooled by the subcooled liquid quickly. The original bubbles were ballooned so rapidly in size after transient volume shrinkage that they 


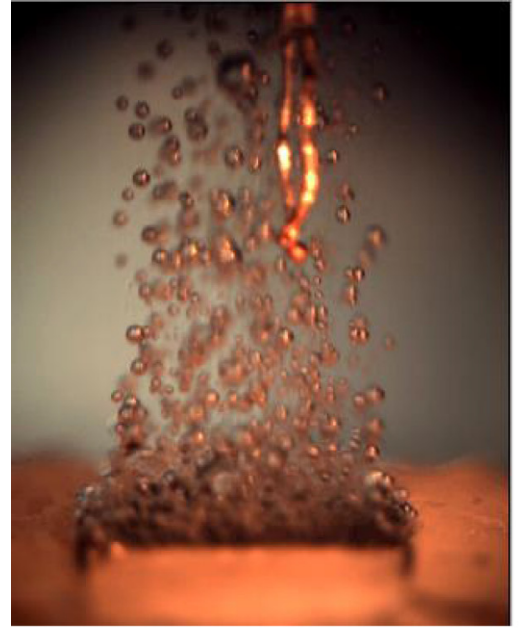

(a) $\tau=-1.016 \mathrm{~s}$

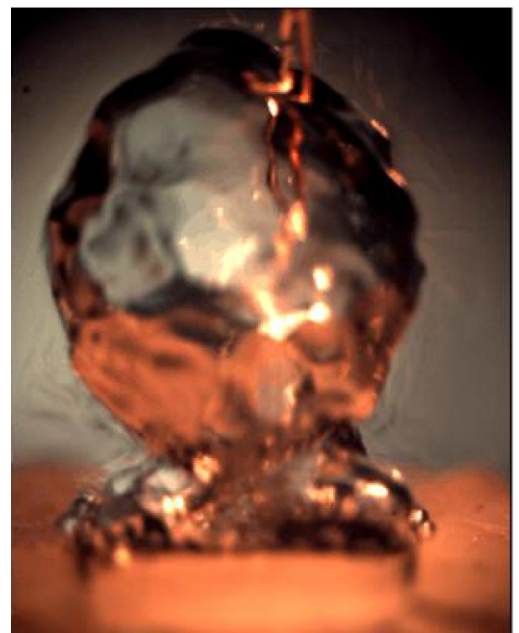

(c) $\tau=0.582 \mathrm{~s}$

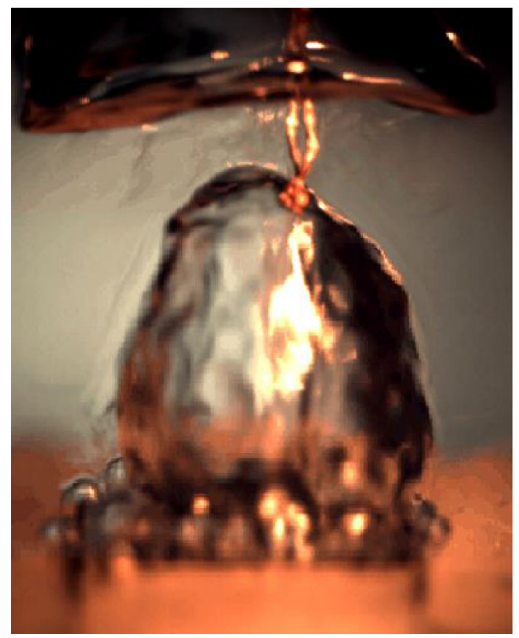

(e) $\tau=0.746 \mathrm{~s}$

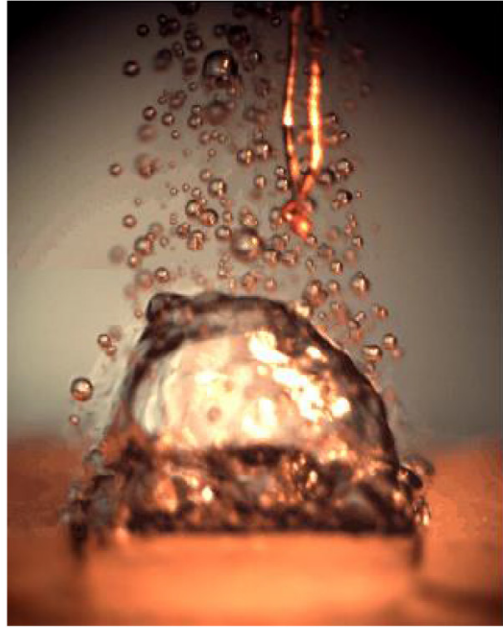

(b) $\tau=0.092 \mathrm{~s}$

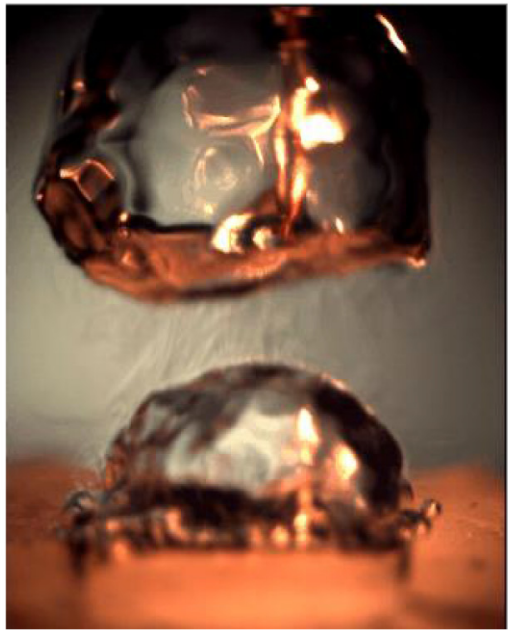

(d) $\tau=0.708 \mathrm{~s}$

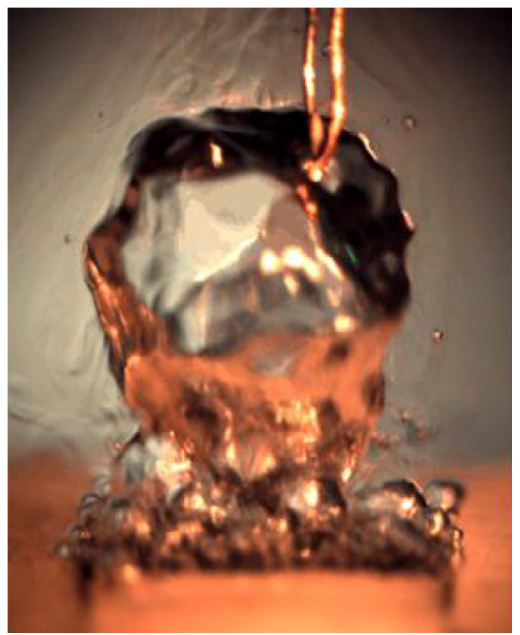

(f) $\tau=0.954 \mathrm{~s}$

Fig. 5. The transition of bubble behavior at moderate heat flux.

merged together to form a new dominant bubble immediately. Compared with the first dominant bubble, which was not affect by the bubble wake at all, it could be found that this dominant bubble was stretched to an ellipsoid shape before detaching from the chip surface owing to the action of the wake caused from previous bubbles, as shown in Fig. 5e and $\mathrm{f}$. The wake-effects actually pulled the underneath bubble up unceasingly, so besides the bubble shape, the ebullition cycle and departure diameter of the bubble in next generation was also significantly influenced. The ebullition cycle shortened to $0.372 \mathrm{~s}$ from the past $0.582 \mathrm{~s}$, and the departure volume was reduced from previous about $904 \mathrm{~mm}^{3}$ to only $493 \mathrm{~mm}^{3}$. 


\subsection{Influence of wake-effects on bubble behaviors at high heat flux}

With increasing the superheat and heat flux (Run ${ }^{\#} 3$, high heat flux, $q=39.54 \mathrm{~W} / \mathrm{cm}^{2}$ ), more and more sites became active, and the bubble frequency at each site increased obviously, as shown in
Fig. 6a. At the initial stage of the microgravity condition, a dominant spherical bubble formed immediately through the collision, adherence, and coalescence of original bubbles (see Fig. 6b). This dominant bubble kept growing up through merging with the surrounding small bubbles. Similar to the phenomena in moderate

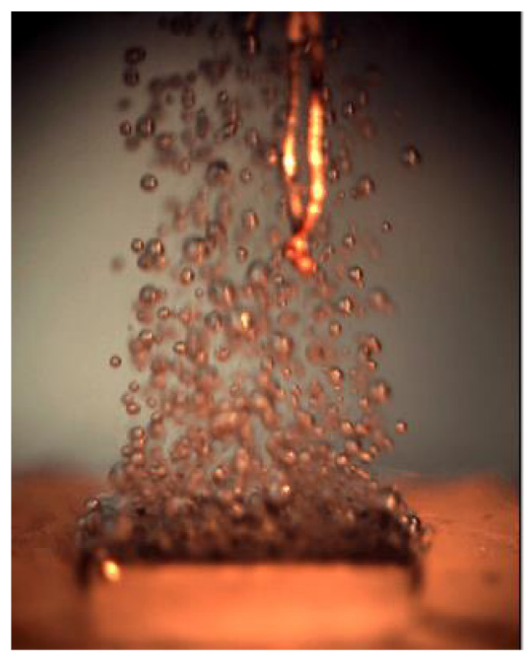

(a) $\tau=-0.940 \mathrm{~s}$

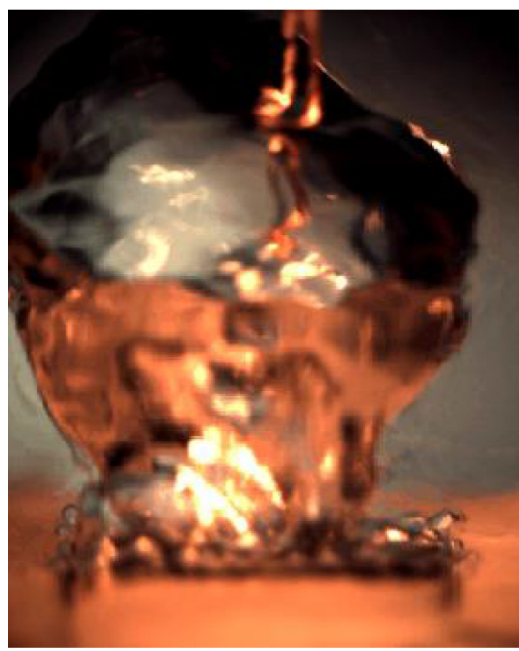

(c) $\tau=0.340 \mathrm{~s}$

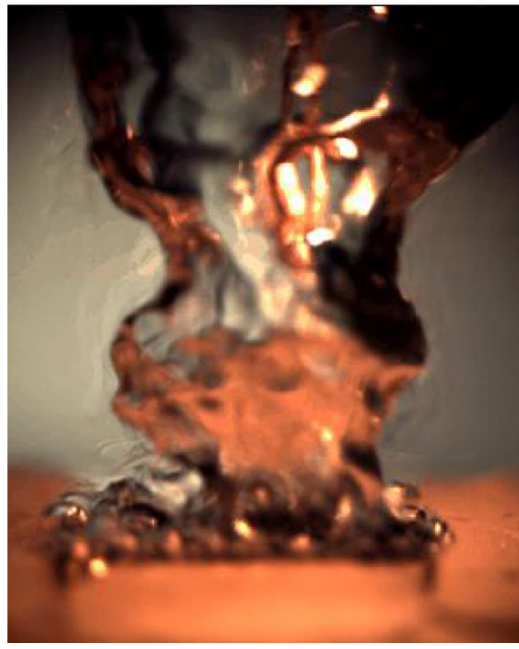

(e) $\tau=0.746 \mathrm{~s}$

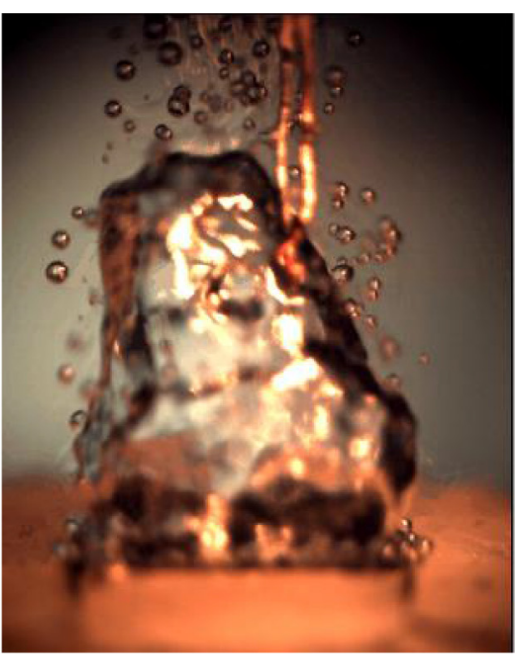

(b) $\tau=0.074 \mathrm{~s}$

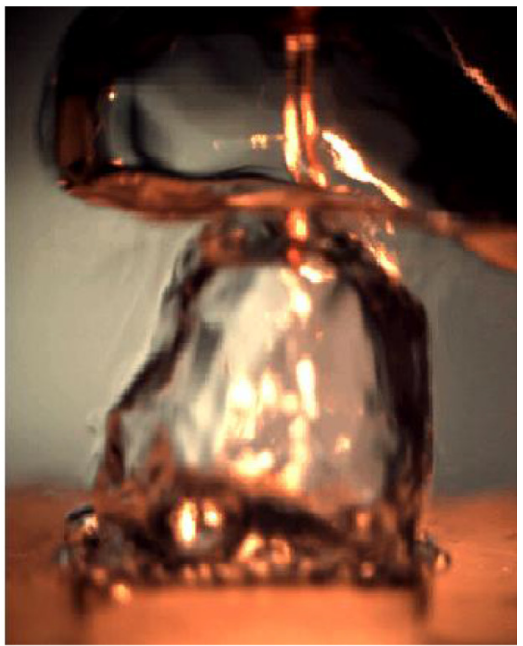

(d) $\tau=0.462 \mathrm{~s}$

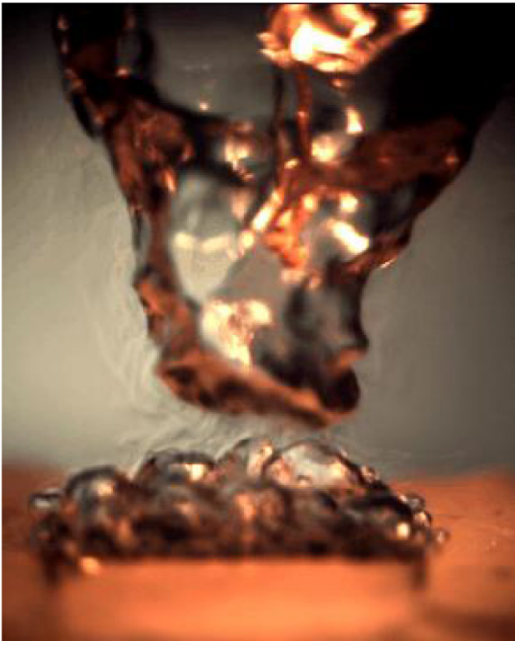

(f) $\tau=0.954 \mathrm{~s}$

Fig. 6. The transition of bubble behavior at high heat flux 
heat flux, the neck of the bubble was also stretched slightly before detaching from the chip surface (as shown in Fig. 6c). After detaching from the heat surface, an intensive shrinkage presented at the trailing edge of the dominant bubble, and the shape of bubble transformed from a ball to a hemisphere configuration with a concave bottom, as shown in Fig. $6 \mathrm{~d}$. At this point a larger low pressure area and a more powerful wake flow field were formed behind the rising bubble. Owning to the high heat flux, the original bubbles wake field were growing up so rapidly that these bubbles started to merge together to form a column of vapor slug rather than detached separately. Then the vapor column was stretched upward under the action of wake-effects and extended towards the departure bubble. Subsequently, the vapor column adhered with the departure bubble and a "mushroom shaped" bubble was formed. This mushroom bubble resumed to grow up due to the continuous production of vapor, which lead to a shape change of bubble from mushroom to a pure vapor column gradually, as shown in Fig. $6 \mathrm{~d}$ and e. The phenomena during this stage were very similar to the process of steam jetting from the heating surface. Eventually the neck of the column shrank rapidly and released from the heating surface for the co-effects of vapor-liquid surface tension and cooling by subcooled liquid. Then the dominant bubble of next generation was beginning to form through the coalescence of small bubbles in tail region, see Fig. 6f. Therefore, the deformation and moving behavior of the dominant bubble and the coalescence of two bubbles in trail flow field were the most striking features during the bubble departure process.

\subsection{The mechanism of heat transfer on micro-pin-finned surface enhanced by wake-effects}

The forces acting on a growing bubble before releasing from the heat surface are shown in Fig. 7. Throughout the bubble growth process, interfacial tension $F_{\mathrm{S}}$ acting along the contact line, viscous drag $F_{\mathrm{d}}$ and Marangoni force $F_{\mathrm{M}}$ tended to hold the bubble in place on heating surface [12]. The buoyancy $F_{\mathrm{b}}$, pressure difference $F_{\mathrm{p}}$ and inertia force $F_{\mathrm{i}}$ associated with motion of the surrounding fluid acted to pull the bubble away [34]. So the total net force of the bubble can be described as follow

$F_{\text {net }}=F_{\mathrm{b}}+F_{\mathrm{p}}+F_{\mathrm{i}}-\left(F_{\mathrm{d}}+F_{\mathrm{s}}+F_{\mathrm{M}}\right)$

These detaching forces became stronger as the bubble became larger, and the bubble would not detach from the chip surface until reached its departure diameter, $D_{\mathrm{d}}$. During the growth process, the volume expansion of dominant bubble mainly depended on the evaporation of microlayer, and its merging with original bubbles

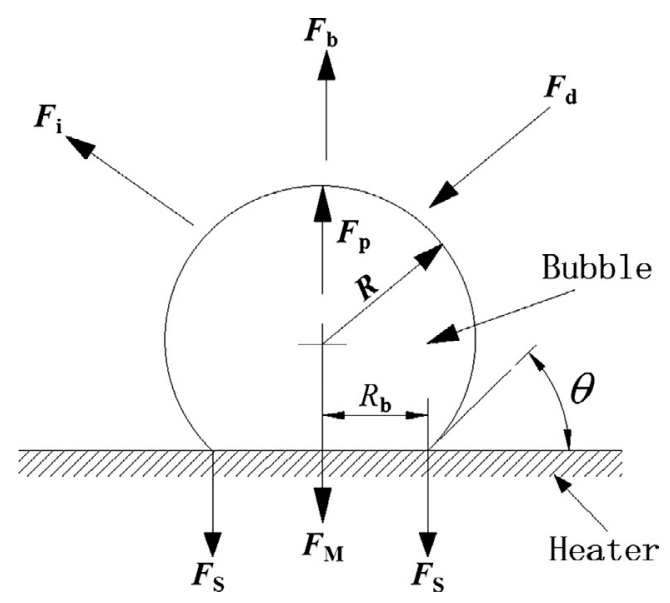

Fig. 7. Forces acting on a growing bubble before detachment. also played a role. However, for the boiling heat transfer in microgravity, the buoyancy effect became weak and the driving force of bubble departure was massively reduced. Whereupon, the heating surface was entirely covered by the dominant bubble before it detached from the chips, especially at high heat flux. At this point, bubble growth was sustained solely by vaporization of the evaporation microlayer between the base of bubble and the heating surface. If the microlayer had been depleted without effective supplement before bubble departure, the temperature of the local surface would rapidly rise with fluctuations. This trend occurred because the dry regions were generally unstable, existing locally at first. Then the entire surface became blanketed with a vapor film and a typical film boiling was observed, leading to an obvious deterioration of boiling heat transfer.

Previous studies have shown that the micro-pin-finned structure could generate a capillary force beneath the bubble, which drove plenty of fresh liquid to contact with the superheated wall for vaporization through the interconnected micro-channels formed by these micro-pin-fins [11,12]. So the dominant bubble could grow up by the continuous vapor supply, and then released smoothly without forming film boiling regime. The bubble diameter at departure in microgravity was about 1-2 orders of magnitude higher than that on the ground, and thus a much more powerful wake flow field was formed under the detached bubble. Comparing with the bubble behaviors on smooth heating surface in a stationary flow field, we found that the combination of wake-effects and micro-pin-fined structure can enhance the heat transfer and prevent dry regions effectively for the following reasons: (1) For the larger departure bubble, a higher pressure gradient could be expected in the wake region, so the horizontal movement of original bubbles became more frequent and severe, which could promote the growth and coalescence of bubble significantly in wake region. (2) The capillary force generated by the interface between the large bubble and the liquid of the microlayer was enhanced dramatically in wake region, so much more fresh liquid was supposed to be inhaled into the micro-pin-fins structure for vaporization through the micro channel. (3) When the subcooled liquid filled the interspace resulting from the rising bubble, the cooling effects on small original bubbles as well as the microconvection heat transfer near the heating surface were both enhanced because of disturbance caused by wake-effects.

\section{Dynamic analyses in wake region}

Fig.8 schematically shows the wake field on micro-finned structure for various heat fluxes. The wake-effects can work on the bubble in next generation in three typical ways (no, partly and fully influenced). In this study, we took the behaviors of bubble which was fully influenced by wake field as example. In order to reveal the mechanisms of action reasonably in a succinctly way, we proposed dynamic studies on typical flow field in wake region based on some reasonable simplifications and hypotheses as follow:

(1) Suppose the detaching bubble is a uniform hemisphere shape with flat bottom, so the weak field is isotropic in the same horizontal round cross-section.

(2) Both the pressure change and the heat transfer between the rising bubble and subcooled liquid are neglected, so the bubble size remains constant.

(3) The thickness of microlayer is extremely thin, and can be consider as the boundary layer thickness before bubble detaching.

(4) The subcooled liquid near heating surface flows so slowly that its forced convection is negligible. 


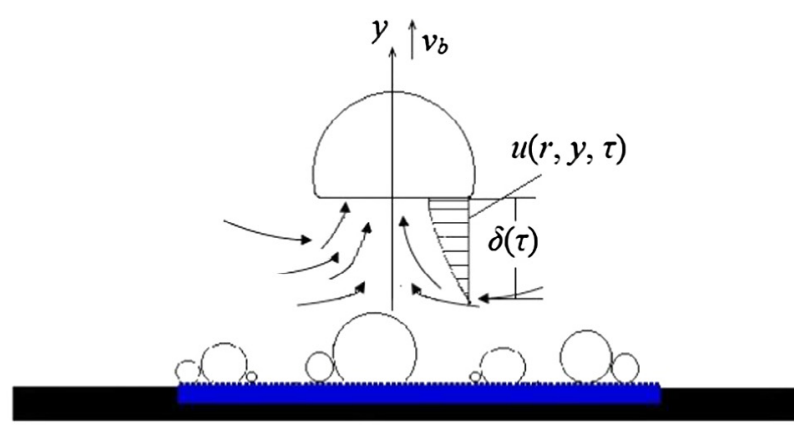

(a) uninfluenced

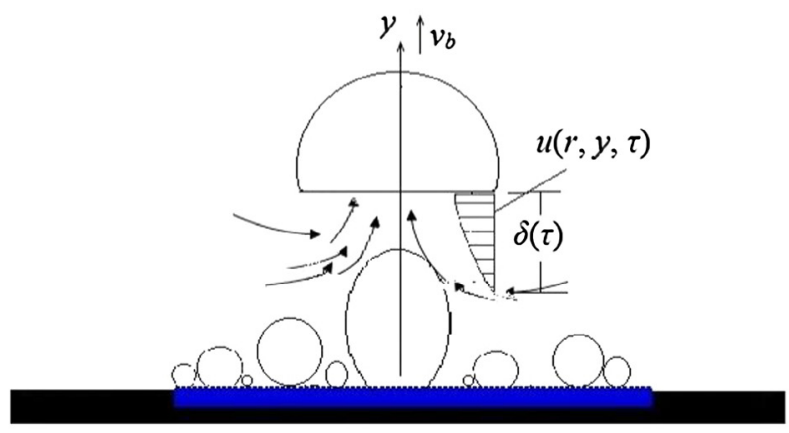

(b) partly influenced

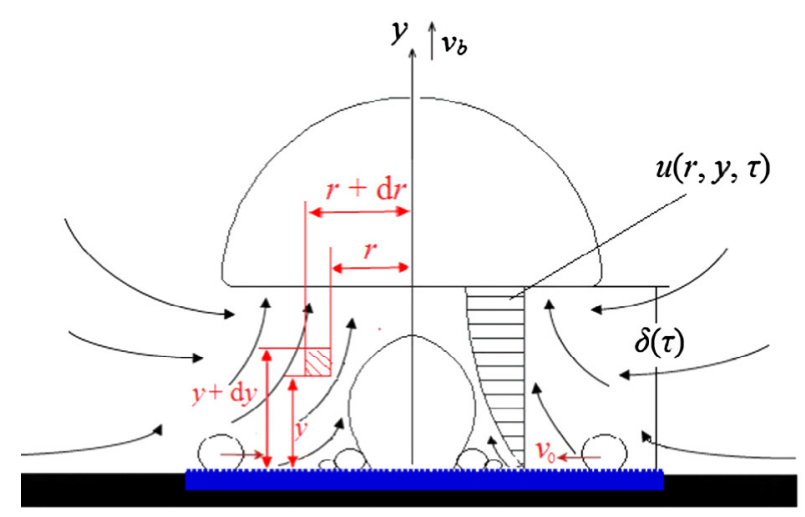

(c) fully influenced

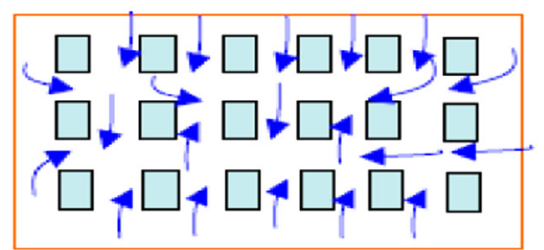

(d) liquid supply through the interconnected micro-channels

Fig. 8. Types of wake field on micro-pin-finned structure.

The rising bubble and its wake had a symbiotic relationship, so the wake field was primarily influenced by the detached bubble. Comprehensive dynamic analyses on flow field and bubble behavior were the key to reveal the mechanism of heat transfer on micro-pin-finned surface enhanced by wakeeffects.

\subsection{Theoretical analyses}

According to assumptions above, the ultimate rising velocity of bubble with radius $r$ can be given by

$v_{b}=\sqrt{\frac{8}{3} \frac{r a_{\mu}\left(\rho_{l}-\rho_{\nu}\right)}{\rho_{l} C_{D}}}$

where $v_{\mathrm{b}}$ is bubble rising; $a_{\mu}$ is acceleration of rising bubble at the microgravity condition; $C_{D}$ is the drag coefficient, when the body is a vapor bubble of negligible density, $C_{D}$ can be commonly defined based on an equivalent projected area, $\pi r^{2}$, as given by Xue [20],

$C_{d}=\frac{5360}{\left[r(d r / d \tau) \rho_{l} / \mu_{l}\right]^{0.79}}$

At this point, the original bubbles together with the subcooled liquid around the rising bubble are being sucked into wake field with horizontal velocity, $u(r, y, \tau)$, to filled the interspace caused by bubble departure. So the flow boundary conditions of the wake field can be written as

$$
\left\{\begin{array}{l}
u(r, 0, \tau)=0 \\
u(r, \delta, \tau)=U(r, \tau)
\end{array}\right.
$$

where $U(r, \tau)$ is the liquid horizontal velocity closed to the bubble bottom, as shown in Fig. 8. Besides, the thermal boundary conditions of the wake field is given by

$\left\{\begin{array}{l}T(0, \tau)=T_{w}(\tau) \\ T\left(\Delta_{T}, \tau\right)=T_{b}\end{array}\right.$

We assume that the thickness of wake field and thermal boundary layer are $\delta(\tau)$ and $\Delta_{T}(\tau)$ respectively. Utilizing assumption (3), the initial condition of wake-effects can be written as

$$
\left\{\begin{array}{l}
\delta(0)=0 \\
\Delta_{T}(0)=\Delta \cdot \operatorname{Pr}^{-1 / 3}
\end{array}\right.
$$

where $\Delta$ is the thickness of microlayer, and $\operatorname{Pr}$ is the Prandtl number.

In order to calculate the flow field in wake region, the mass balance should be considered first. We consider the equilibrium of a small cylindrical ring element cut out of the liquid, as shown in Fig. 8c, the inner and outer radii of the ring are $r$ and $r+d r$ respectively, the height of the cylinder is $\mathrm{d} y$. The differential form of liquid increase in the element can be expressed as

$\dot{m}(\tau)=2 \pi \rho_{l} r \frac{d y}{d \tau} d r(\tau)$

The liquid flowing into the element per unit time is

$\left\{\begin{array}{l}\dot{m}_{H-i n}=2 \pi \rho_{l} r \int_{0}^{\delta(\tau)} u(r, y, \tau) d y \\ \dot{m}_{V-i n}=2 \rho_{l} \delta \int_{0}^{\frac{d_{d}}{2}} v(r, y, \tau) d r\end{array}\right.$

where subscript $\mathrm{H}$ and $\mathrm{V}$ mean horizontal and vertical components respectively. The mass flowing out of the small cylinder in unit time is given

$\left\{\begin{array}{l}\dot{m}_{H-\text { out }}=2 \pi \rho_{l}\left[r \int_{0}^{\delta(\tau)} u(r, y, \tau) d y+\frac{\partial}{\partial r}\left(r \int_{0}^{\delta(\tau)} u(r, y, \tau) d y\right)\right] \\ \dot{m}_{V-\text { out }}=2 \rho_{l}\left[\delta \int_{0}^{\frac{d_{d}}{2}} v(r, y, \tau) d r+\frac{\partial}{\partial y}\left(\delta \int_{0}^{\frac{d_{d}}{2}} v(r, y, \tau) d r\right)\right]\end{array}\right.$

According to the conservation of mass, the incremental mass of the small cylindrical ring element can be calculated from

$\dot{m}(\tau)=\dot{m}_{\text {in }}-\dot{m}_{\text {out }}$

Substituting Eqs. (7)-(9) into Eq. (10), and simplifying the equation, we obtain 
$\frac{1}{r} \frac{\partial}{\partial r}\left(r \int_{0}^{\delta(\tau)} u(r, y, \tau) d y\right)+\frac{1}{\pi \delta} \frac{\partial}{\partial y}\left(\delta \int_{0}^{\frac{d_{d}}{2}} v(r, y, \tau) d r\right)=-\frac{d y}{d \tau}$

The distribution of horizontal velocity $u(r, y, \tau)$ and vertical velocity $v(r, y, \tau)$ in wake region and their relations to the thickness of wake field, $\delta(\tau)$, are both the important parameters for solving Eq. (11). Base on the flow boundary conditions, $u(r, y, \tau)$ and $v(r, y, \tau)$ can be expressed as

$$
\left\{\begin{array}{l}
\frac{u(r, y, \tau)}{U(r, \tau)}=2 \xi-2 \xi^{3}+\xi^{4} \\
\frac{v(r, y, \tau)}{V(r, \tau)}=1-3 \eta+3 \eta^{2}-\eta^{3}
\end{array}\right.
$$

where $\xi=\frac{y}{\delta(\tau)}, \eta=\frac{D_{d}}{2 r}$. Combining Eq. (11) through Eq. (12), the following relation is obtained after some manipulation.

$\frac{1}{r} \frac{\partial}{\partial r}[r U(r, \tau)]+\frac{1}{\pi \delta} \frac{\partial}{\partial y}[\delta V(r, \tau)]=-\frac{10}{7} \frac{1}{\delta(\tau)} \frac{d y}{d \tau}$

From a simple forces balance on a bubble rising in a semiinfinite liquid, the rising velocity can be obtained from

$v(\tau)=v_{b}\left(1-e^{-\tau / \tau_{l}}\right)$

where $\tau_{l}$ is the time required for bubble to reach $v_{b}$ and can be obtained from the experiments. The rising velocity can also be expressed in differential form

$v(\tau)=\frac{d \delta}{d \tau}$

The initial condition is $\delta=0$ when $\tau=0$. So the thickness of the wake region can be cast from Eqs. (14) and (15)

$\delta(\tau)=c\left[\frac{\tau}{\tau_{l}}-\left(1-e^{-\tau / \tau_{l}}\right)\right]$

where $c$ is an integral constant. Substituting Eq. (16) into Eq. (11), we obtain

$\frac{1}{r} \frac{\partial}{\partial r}[r U(r, \tau)]+\frac{1}{\pi \delta} \frac{\partial}{\partial y}[\delta V(r, \tau)]=-\frac{10}{7} \frac{1}{\tau_{l}} \frac{1-e^{-\tau / \tau_{l}}}{\frac{\tau}{\tau_{l}}-\left(1-e^{-\tau / \tau_{l}}\right)}=f\left(\tau, \tau_{l}\right)$

Neglecting the small terms such as viscous convective and shear force between vapor and liquid, the momentum equations in vertical direction can be written as

$\frac{\partial^{2} v(r, y, \tau)}{\partial r^{2}}=\frac{-\left(\rho_{l}-\rho_{v}\right) g_{\mu}}{\mu}$

Integration of Eq. (18) with boundary conditions

$\left\{\begin{array}{l}v(r, 0, \tau)=0 \\ \frac{\partial v(r, y, \tau)}{\partial r}=0, \quad \text { at } r=\frac{D_{d}}{2}\end{array}\right.$

We can obtain vertical velocity

$v(r, y, \tau)=\frac{g_{\mu}}{\mu}\left(\rho_{l}-\rho_{v}\right)\left(\delta r-\frac{r^{2}}{2}\right)$

Thus, combining Eq. (17) and (20) with Eq. (12), the relations between horizontal and vertical velocities are given

$\frac{u(r, y, \tau)}{r\left(2 \xi-2 \xi^{3}+\xi^{4}\right)}+\frac{v(r, y, \tau)}{\pi \delta\left(1-3 \eta+3 \eta^{2}-\eta^{3}\right)}=\frac{1}{2} f\left(\tau, \tau_{l}\right)$

\subsection{Analyses of influencing factors}

Fig. 9 shows the functional relationship between the departure diameters of dominant bubble and the durations of wake-effects, the experimental data of growth time of the bubble in next generation are also illustrated in this figure. It can be found that the time period of wake-effects increased with increasing departure diameter but the rising range decreased gradually with the increase of bubble diameter due to the larger drag force. Moreover, although the growth cycles increased fast with the bubble diameter, the durations of wake-effects still lasted longer than the time periods of the bubble in next generation for all experimental data. It means the wake field caused from the detached bubble always influences the dominant bubble of next generation during its ebullition cycle even after releasing from the heating surface.

Fig. 10 shows a theoretical function relation between the thickness and the duration of wake field. Both of the two variables were dealt with dimensionless method to make the function appropriate for various departure diameters. Here, assuming the wake-effects duration $\tau_{0}$ ends after the dominant bubble of next generation released from the heat surface. As shown in the figure, the thickness of wake region increased with the duration of wake-effects in form of power function. Besides, the experimental data of bubble diameter along with time are displayed as well in Fig. 10. The 2nd dominant bubble grew up rapidly through merging with small original bubbles and detached from the heating surface after reaching departure diameter. However, the bubble diameter was always smaller than the thickness of wake region caused by $1 \mathrm{st}$ bubble, so the whole 2 nd bubble was surrounded by the wake field during its ebullition cycle. Due to the assumption above, the influence of wake field caused from 1st bubble was considered to vanish once the 2nd bubble detached. However, It's important to note that the bubble in 3rd generation (3rd bubble) might be affected by the combined action of two wake fields in the initial stage if the frequency of bubble release was high enough.

The velocity distributions along the thickness direction of wakeeffects at a given time are shown in Fig. 11. Both the horizontal component and the vertical component of the velocity approached zero near the heating surface. As the $\delta / \delta_{0}$ values increased, the horizontal velocity $u$ increased exponentially but vertical component $v$ increased linearly with the duration of wake field, so the horizontal velocity was lower than vertical velocity but it increased faster than $u$. The vertical velocity can help the dominant bubble detach from the heating surface in a smaller size and move upward faster. By comparison, the horizontal component promoted the collision, coalescence and movement of bubbles. Both of these two components would be advantageous to enhance heat transfer and improve the critical heat flux, so a more uniform distribution of temperature and heat flux can be obtained in wake field.

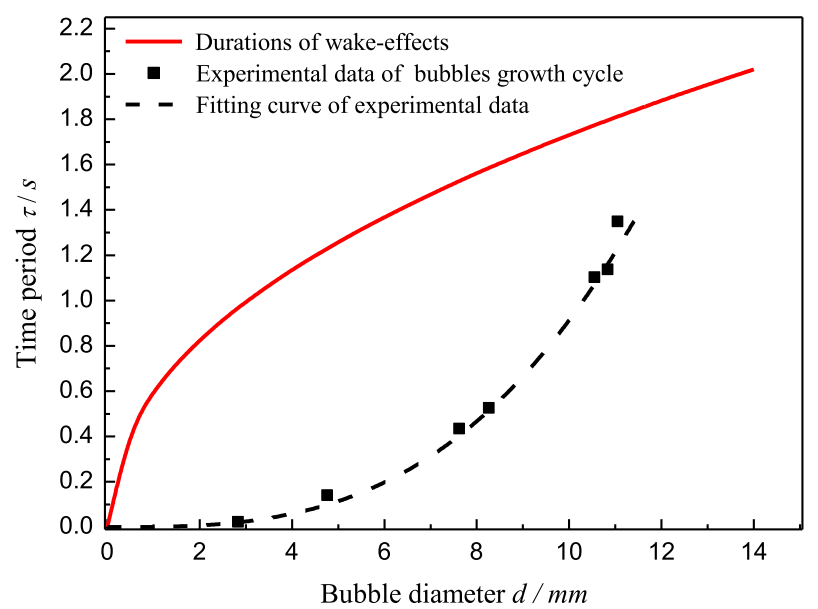

Fig. 9. Relationship between departure diameters and the durations of wakeeffects. 


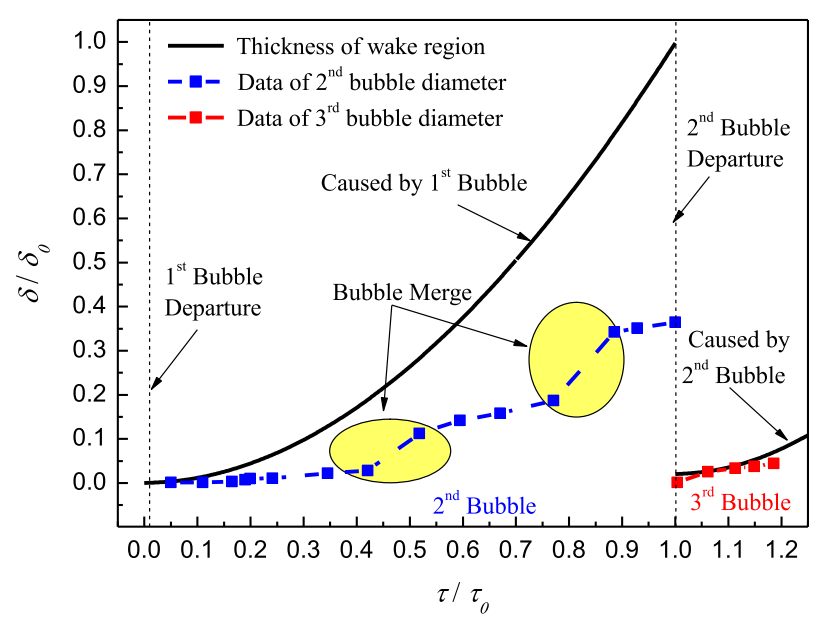

Fig. 10. Relation between the thickness and the duration of wake field.

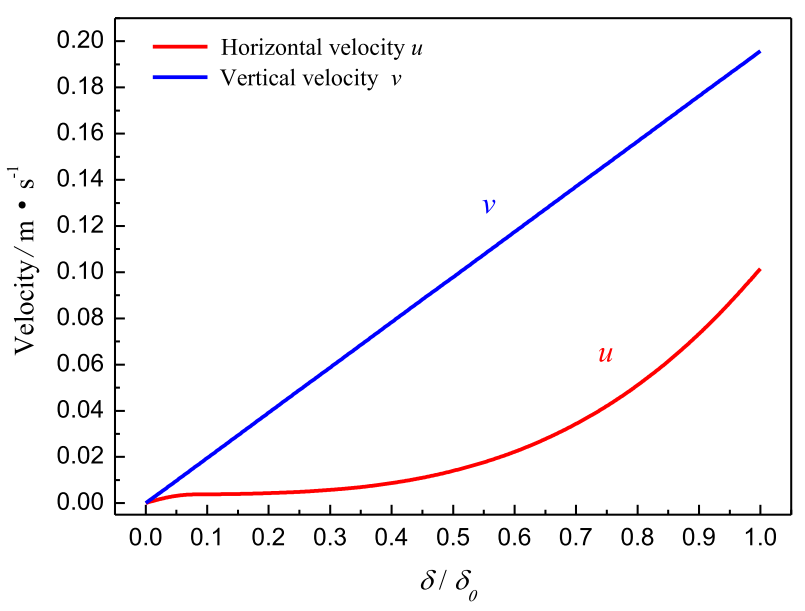

Fig. 11. Velocity distributions along the thickness direction of wake-effects.

\section{Conclusions}

In the present study, the influences of wake on bubble dynamics under various heat fluxes have been experimentally investigated in microgravity environment by utilizing the drop tower facility in Beijing. In addition, the flow field and bubble behavior in wake region were briefly analyzed based on some reasonable simplifications and hypotheses. The following conclusions can be obtained from the above studies.

(1) In microgravity, a small but observable wake region existed behind the departure bubble at low heat flux, $q=12.53 \mathrm{~W} /$ $\mathrm{cm}^{2}$, so the surrounding subcooled fluid can flow into the wake field to cool the original bubbles. However, the wake-effects had little influence on dynamics behavior of bubble in next generation due to the limited volume and low rising velocity of this departure bubble.

(2) The dominant bubble grew larger and released faster from the heat surface at moderate heat flux, $q=27.89 \mathrm{~W} / \mathrm{cm}^{2}$, so the duration and influence range of the wake-effects were both increased significantly. In the wake field, the horizontal flow of the liquid on micro-pin-finned silicon chips promoted the collision, coalescence and movement of bubbles. More importantly, the vertical flow of liquid phase exerted an upward force on bubbles, which can effectively shorten the growth cycle and decrease the departure diameter of bubble.
(3) A column of vapor slug was formed in the wake field behind the rising bubble at high heat flux, $q=39.54 \mathrm{~W} / \mathrm{cm}^{2}$. Whereafter, this column merged with the departure bubble to form a large column, and then the column released from the heat surface through a neck shrinkage process.

(4) Furthermore, fresh liquid could easily be inhaled into the micro-pin-finned structure owning to the negative pressure in wake region. This process could supply sufficient liquid for the growth of bubble, avoiding film boiling. Therefore, the interaction between the micro-pin-finned structure and the wake effect promoted the process of bubble coalescence and departure effectively, so the process of heat transfer was significantly improved on micro-pin-finned surface.

(5) The theoretical analyses showed that the durations of wakeeffects lasted longer than the time periods of the bubble in next generation, and the bubble diameters were also smaller than the thickness of wake region. Therefore, the dominant bubble of next generation was influenced by the wake field during its ebullition cycle, which is consistent with the experimental phenomenon.

\section{Acknowledgments}

We gratefully acknowledge the financial support from the National Natural Science Foundation of China - China under the Grants of 51306141 and 51225601, and the support from the Key Laboratory of Microgravity/CAS for experiments utilizing the drop tower Beijing. The author would like to thank the Drop tower staffs for their help in the present experiments.

\section{References}

[1] M.Z. Yuan, J.J. Wei, Y.F. Xue, et al., Subcooled flow boiling heat transfer of FC-72 from silicon chips fabricated with micro-pin-fins, Int. J. Therm. Sci. 48 (2009) $1416-1422$.

[2] A.X. Ma, J.J. Wei, M.Z. Yuan, et al., Enhanced flow boiling heat transfer of FC-72 on micro-pin-finned surfaces, Int. J. Heat Mass Transfer 52 (2009) 2925-2931.

[3] P. Di Marco, Influence of force fields and flow patterns on boiling heat transfer performance: a review, J. Heat Transfer - Trans. ASME 134 (2013) 030801-1030801-15.

[4] C. Konishi, I. Mudawar, Review of flow boiling and critical heat flux in microgravity, Int. J. Heat Mass Transfer 80 (2015) 469-493.

[5] J. Straub, Boiling heat transfer and bubble dynamics in microgravity, Adv. Heat Transfer 35 (2001) 57-172.

[6] J.F. Zhao, G. Liu, S.X. Wan, et al., Bubble dynamics in nucleate pool boiling on thin wires in microgravity, Microgravity Sci. Technol. 20 (2008) 81-89.

[7] J.F. Zhao, S.X. Wan, G. Liu, et al., Subcooled pool boiling on thin wire in microgravity, Acta Astronaut. 64 (2009) 188-194.

[8] J.P. Koeln, J.C. Boulware, H. Ban, et al., Observations on braided thin wire nucleate boiling in microgravity, Int. J. Heat Fluid Flow 32 (2011) 973-981.

[9] R.T. Munro, J.P. Koeln, W. Andrew, Phase change heat transfer and bubble behavior observed on twisted wire heater geometries in microgravity, Int. J. Heat Fluid Flow 47 (2014) 21-30.

[10] D.M. Qiu, V.K. Dhir, D. Chao, et al., Single-bubble dynamics during pool boiling under low gravity conditions, J. Thermophys. Heat Transfer 16 (2002) 336345.

[11] Y.F. Xue, J.F. Zhao, J.J. Wei, et al., Experimental study of nucleate pool boiling of FC-72 on micro-pin-finned surface under microgravity, Int. J. Heat Mass Transfer 63 (2013) 425-433.

[12] Y.H. Zhang, J.J. Wei, Y.F. Xue, et al., Bubble dynamics in nucleate pool boiling on micro-pin-finned surfaces in microgravity, Appl. Therm. Eng. 70 (2014) 172182.

[13] R. Raj, J. Kim, J. McQuillen, Pool boiling heat transfer on the International space station: experimental results and model verification, J. Heat Transfer - Trans. ASME 134 (2012) 101504-1-101504-14.

[14] H. Ohta, S. Baba, Boiling experiments under microgravity conditions, Exp. Heat Transfer - J. Therm. Energy Gener. Transp. Storage Convers. 26 (2013) 266295.

[15] Y. Yang, L.M. Pan, L.C. Xue, Single bubble growth at different gravity and the effects of microgravity on Marangoni convection, in: 20th International Conference on Nuclear Engineering and the ASME 2012 Power Conference, Anaheim, 2012, pp. 647-652.

[16] J. Straub, Origin and effect of thermocapillary convection in subcooled boiling. Observations and conclusions from experiments performed at microgravity, Ann. N.Y. Acad. Sci. 974 (2002) 348-363. 
[17] E. Aktinol, G.R. Warrier, V.K. Dhir, Single bubble dynamics under microgravity conditions in the presence of dissolved gas in the liquid, Int. J. Heat Mass Transfer 79 (2014) 251-268

[18] O. Kannengieser, C. Colin, W. Bergez, Pool boiling with non-condensable gas in microgravity: results of a sounding rocket experiment, Microgravity Sci. Technol. 22 (2010) 447-454.

[19] J.F. Zhao, G. Liu, S.X. Wan, et al., Bubble dynamics in nucleate pool boiling on thin wires in microgravity, Microgravity Sci. Technol. 20 (2008) 81-89.

[20] Y.F. Xue, J.F. Zhao, J.J. Wei, et al., Experimental study of nucleate pool boiling of FC-72 on smooth surface under microgravity, Microgravity Sci. Technol. 23 (Suppl. 1) (2011) S75-S85.

[21] C.D. Henry, J. Kim, J. McQuillen, Dissolved gas effects on thermocapillary convection during boiling in reduced gravity environments, Heat Mass Transfer 42 (2006) 919-928.

[22] V.K. Dhir, G.R. Warrier, E. Aktinol, et al., Nucleate Pool Boiling Experiments (NPBX) on the international space station, Microgravity Sci. Technol. 24 (2012) 307-325.

[23] J. Wu, V.K. Dhir, Numerical simulation of dynamics and heat transfer associated with a single bubble in subcooled boiling and in the presence of noncondensables, J. Heat Transfer - Trans. ASME 133 (2011) 041502-1041502-14

[24] J. Straub, Highs and lows of 30 years research of fluid physics in microgravity, a personal memory, Microgravity Sci. Technol. 18 (2006) 14-20.

[25] S.X. Wan, J.F. Zhao, G. Liu, Dynamics of discrete bubble in nucleate pool boiling on thin wires in microgravity, J. Therm. Sci. 18 (2009) 13-19.
[26] J. Kim, J.F. Benton, D. Wisniewski, Pool boiling heat transfer on small heaters: effect of gravity and subcooling, Int. J. Heat Mass Transfer 45 (2002) 39193932.

27] C.D. Henry, J. Kim, A study of the effects of heater size, subcooling, and gravity level on pool boiling heat transfer. Int. J. Heat Fluid Flow 25 (2004) 262-273.

[28] R. Rishi, J. Kim, J. McQuillen, Subcooled pool boiling in variable gravity environments, J. Heat Transfer - Trans. ASME 131 (2009) 091502-1-091502 10.

[29] T. Oka, Y. Abe, Y.H. Mori, et al., Pool boiling of n-Pentane, CFC-113, and water under reduced gravity: parabolic flight experiments with a transparent heater, J. Heat Transfer - Trans. ASME 117 (1995) 408-417.

30] T. Oka, Y. Abe, Y.H. Mori, et al., Pool boiling heat transfer in microgravity (experiments with CFC-113 and water utilizing a drop shaft facility), JSME Int. J. 39 (1996) 798-807.

31] R.R. Souza, J.C. Passos, E.M. Cardoso, Confined and unconfined nucleate boiling under terrestrial and microgravity conditions, Appl. Therm. Eng. 51 (2013) 1290-1296.

[32] J.J. Wei, H. Honda, Effects of fin geometry on boiling heat transfer from silicon chips with micro-pin-fins immersed in FC-72, Int. J. Heat Mass Transfer 46 (2003) 4059-4070.

[33] H. Honda, J.J. Wei, Enhanced boiling heat transfer from electronic components by use of surface microstructures, Exp. Therm. Fluid Sci. 28 (2004) 159-169.

[34] S. Karri, Dynamics of bubble departure in micro-gravity, Chem. Eng. Commun. 70 (1) (1988) 127-135. 